\title{
Digitization of the Mary Hamilton Papers
}

\author{
Anne-Christine Gardner, Marianne Hundt and Moira Kindlimann, \\ Universität Zürich
}

\begin{abstract}
Held at The John Rylands Library, Manchester, the Mary Hamilton Papers are a valuable, but still largely untapped resource for linguistic, cultural and literary studies focussing on the late eighteenth century. In her diaries Lady Mary Hamilton (1756-1816) documents daily life and friendships with intellectual figures of the time, for instance Horace Walpole and members of the Bluestocking circle, which included Elizabeth Montagu and Frances Burney. The archive also contains letters written to Lady Mary Hamilton by her family and other members of her social network.

The aim of this project is to prepare a digital edition of materials from the Mary Hamilton Papers with TEI-conformant XML mark-up, in which both a facsimile of the manuscripts and their transliterations (preserving the original spelling, punctuation and layout) will be displayed. In addition, the edition will offer rich meta-data and mark-up of places, persons and literary works, as well as normalized spellings, which will assist searches for linguistic features differing from Present-day English such as (non-) capitalisation (e.g. english, Breakfast) and past tense spellings like dress'd and staid.

Drawing on material from the Mary Hamilton Papers and the Corpus of Late Modern English Prose, we provide a case study to illustrate the usefulness of the Mary Hamilton Papers for the study of language change and social networks in the Late Modern period.
\end{abstract}

\section{Introduction}

Ego documents, such as private letters, diaries and autobiographical writings, are an important source not only for historians (e.g. Loetz 2015; Ulbrich, von Greyerz and Heiligensetzer 2015) and literary critics (e.g. Bradford 2010), but also for historical (socio-)linguists (see e.g. van der Wal and Rutten 2013). Historians, in particular, have digitized letter collections and diaries for the pur- 
poses of research (resulting in collections such as the 'British Army War Diaries 1914-1922'), ${ }^{1}$ and linguists started by compiling corpora of private letters. For the study of language change, existing resources have already shown that we can learn a lot about, for instance, the influence of an individual's social network on their language use. But especially early letter collections, such as the Corpus of Early English Correspondence (CEEC), are based mainly on edited rather than manuscript material, limiting the usefulness of such corpora to some extent. Similarly, digital editions of diaries are not necessarily produced with the needs of linguists in mind and 'silently' expand abbreviations or remove dashes that fill the end of an entry. ${ }^{2}$ More recent letter corpora such as The Corpus of Scottish Correspondence (CSC), as well as digital editions generally (e.g. Honkapohja 2013; Marttila 2014), show an increased concern with preparing databases that represent the original sources as faithfully as possible. This article reports of an ongoing digitization project of the ego documents connected with an eighteenth-century English female aristocrat, Lady Mary Hamilton (1756-1816). ${ }^{3}$ The materials will be used for the study of language change at the turn of the eighteenth to the nineteenth century, but they are ultimately a useful source of information for scholars in neighbouring fields, such as social and cultural historians and literary scholars. ${ }^{4}$

Lady Mary Hamilton was third lady attending the daughters of Queen Charlotte at the court of George III between 1777 and 1782, and in the following years she enjoyed life as an independent woman in London, where she had contacts with the Bluestocking network, a circle of intellectuals around Elizabeth Montagu, Elizabeth Vesey, Frances Burney and others (amongst them also Samuel Johnson and Horace Walpole). ${ }^{5}$ Lady Mary Hamilton kept a personal diary during a period of 21 years (i.e. in 1776, 1782-1785 and 1797) and has been called the female Pepys of the late eighteenth century since she not only documents her own every-day life, but also comments on important events as well as on writers and political figures. Samuel Pepys, a businessman, naval officer and member of parliament is one of the most well-known figures in British history of the seventeenth century, and a major reason why he is so well known that he even features in primary school lessons is the fact that he kept a diary for about a decade. ${ }^{6}$ Presenting similarly rich detail on life in late eighteenth-century England, Lady Mary Hamilton's diaries therefore constitute a valuable resource for a wide variety of research interests.

On the basis of digital images of the manuscript volumes of these diaries, we are currently building an online edition of the text conforming with TEI standards and full XML annotation. Both the transliteration of the manuscript material and the images will be published online, with the digital edition linked to the 
manuscript pages to allow for direct comparison. The transliterations will enable online searches of the text, permitting basic word searches and sophisticated linguistic queries on the one hand, but also providing background information on the persons and events mentioned in the diary text. ${ }^{7}$

The paper has two different aims, to give background on the digitization (i.e. a more technical goal) and to illustrate how the materials can be used in historical linguistic research. The following two sections offer an introduction to the general methodology of the digitization project. Section 2 presents the aims of the project in greater detail, while Section 3 describes the steps involved in creating transliterations in annotated XML-format of the manuscript material and in preparing the online version, specifying the type of information which will be preserved and added in the digital edition. More detailed aspects regarding the annotation process, metadata collection and online access of the Mary Hamilton Papers will be treated at a later stage when further materials have been digitized, and challenges as well as decisions regarding, for instance, the adaptation of TEI guidelines can be reported on more comprehensively. On the basis of a case study, Section 4 illustrates how the Mary Hamilton Papers can be fruitfully used to investigate language change and variation in late eighteenth-century English, and to gain new insights into the Bluestocking network in particular, and the role of social networks for linguistic change in general. The paper concludes with an appraisal of the Mary Hamilton Papers for further linguistic study, as well as an outlook on further plans for the digitization project once the first phase is completed.

\section{Aims of the digitization project}

The proposed electronic edition of the Mary Hamilton Papers comprises a selection from the over 2,100 letters to and from Lady Mary Hamilton, 16 diaries, as well as various notes and literary transcripts. It aims to cater to the needs of researchers from different fields who are interested, for instance, in the study of late eighteenth-century English language, social networks (especially that of the so-called Bluestockings) and ego documents. In order to be able to satisfy the different requirements of these various disciplines, the edition strives to maintain the highest degree of faithfulness to the original manuscript text. This goes beyond preservation of original spellings (including alternate glyphs such as the long $\mathrm{s}<\uparrow>$ ) and grammar, but also takes into account original layout (indentations, underlining, insertions of additional paper slips, drawings, etc.). The digital edition thus aims to preserve the integrity of the original manuscript material as far as possible, while at the same time providing normalization (spelling, 
grammar, self-corrections, textual insertions etc.) in the XML annotation that will enable researchers to retrieve information for analysis from the digitized material automatically in a maximally efficient manner. Digital editions, unlike on-line print editions, facilitate the encoding of many layers of information (including cross-references to biographical information collected in a database). This rich source of information can be accessed electronically while at the same time allowing to preserve the original source and even linking the digital images to the transliterated electronic text, thus leaving the edition open to further scrutiny, improvement and correction (see e.g. the online facsimile edition of Jane Austen's fiction manuscripts by K. Sutherland 2010).

Faithfulness to the manuscript material is an important prerequisite especially - but not only - for philological and linguistic analysis; Lass (2004: 2122) draws a parallel between working with manuscript materials and archaeological digs or a crime scene:

All three are venues whose detailed history needs to be reconstructed. It is a commonplace in archaeology and forensic praxis that as far as possible (a) the scene must not be contaminated by material brought in by the investigator or anyone else, and (b) the chain of custody (the sequence of provenances of all objects found on the scene) must be immaculate. [...]

Any interference with these witnesses is a potential contamination: either intrusion of alien material into the historical record, or a loss of genuine material. Both are falsifications, both equally destructive.

[...] the maintenance of forensic cleanliness in a field full of potentially corrupted information sources. Among the most dangerous of these corrupt sources are edited texts. They are dangerous because of the degree to which they are trusted and characteristically regarded as 'data', worthy of inclusion in historical corpora.

Digitization of manuscript material for historical research often normalizes the variation found at the level of language use, as this aspect is (largely) irrelevant for historical study. Historical linguistic corpora, on the other hand, typically provide relatively impoverished databases with respect to biographical, sociological or geographical background information that goes beyond the level of the author of individual texts. Moreover, without normalization of variant spellings or abbreviations, historical corpora are not ideal for the purposes of historical investigation as variation is an obstacle for efficient information retrieval. 
These shortcomings can be avoided in a digital edition that makes use of cutting-edge annotation schemes (see Section 2) and publication of both transliterations and images of the original manuscript, in addition to a rich database with background information. The digital edition envisaged in this project will thus respect the needs of various kinds of research.

In order to achieve the different aims of the digital edition, a framework for a TEI (Text Encoding Initiative)-conformant XML annotation of the materials in the collection was developed (Kindlimann 2014). The guidelines provided by the TEI offer extensive mark-up rules and specific recommendations for structural, visual, and conceptual features of text, as well as background and metainformation. This scheme has been adapted and customized according to the needs of this edition. One of the many advantages of working with TEI-conformant mark-up is that the edition will be maximally compatible with the annotation of other corpora, as well as tools and applications such as part-of-speech taggers and grammatical parsers, i.e. annotation levels that are valuable for linguists.

\section{From manuscript to edition}

An event which Lady Mary Hamilton describes at great length in her diary on 13 August 1784 is her viewing of a hot air balloon exhibited at the Lyceum, which was to be launched the following day from Chelsea Hospital Garden, in the presence of King George III and Queen Charlotte. Figure 1 shows a small extract from this diary entry, illustrating several peculiarities of manuscripts in general, and eighteenth century manuscripts in particular, which any kind of edition needs to address. These peculiarities include the abbreviated name $A$ Maria, the contractions join' $d$ and ask' $d$, the lack of capitalization at the beginning of a sentence in $h e$, and the form $y^{e}$ for the. A non-linear edition, such as one using XML encoding, has the distinct advantage of not having to choose between preservation of authenticity, searchability, and readability. Instead, it provides the possibility to encode several layers of information in one document, and accordingly utilize these different layers for different purposes. The path to such a non-linear edition comprises three steps: (1) the raw, authentic transliteration, (2) the XML annotation, which adds variant versions and meta-information, thus making comprehensive searchability possible, and (3) the normalized version for browsing, which displays output in an easily readable version while maintaining the link with the underlying original manuscript text. 




Figure 1: Example from the diary entry for 13 August 1784 (HAM/2/13)

\subsection{Raw transliteration}

The first step, the raw transliteration, consists simply of typing a document, such as the 13 August 1784 diary entry, into a text file. At this stage, care must be taken to transliterate the text faithfully and completely, so that no potentially salient information is lost. This means, for example, including word divisions at line breaks along with any division markers, keeping alternate characters (most prominently the long $\mathrm{s}<\Gamma>$ ), and all variant or potential misspellings and abbreviations, as well as additions, deletions and other modifications.

It is possible to conflate this step with the next one, and incorporate the $\mathrm{XML}$ annotation directly into the initial transliteration. However, experience has shown that persons unfamiliar with XML coding struggle somewhat to adapt to the details of the notation. Even for more experienced persons, the text quickly becomes difficult to read. Therefore, this initial step, if done carefully, can save a certain amount of time, as some annotation can be added directly into the transliteration without the need to constantly consult the manuscript. To further ease the transition between transliteration and annotation, it is possible to add some basic pseudo-annotation. This can be especially helpful for frequently occurring elements, such as the form $\left\langle\mathrm{y}^{\mathrm{e}}\right\rangle$ for the, which can be initially transcribed as 'ye_S' (meaning that this represents a spelling variation), and later globally replaced by the complete XML code.

\subsection{XML annotation}

Every document in the digital edition is split into three different components using the TEI-conventions: header, facsimile, and text. The header contains all meta-information, the facsimile a set of images of the source text, while the text constitutes the core of the edition, i.e. the XML-annotated transliteration.

The meta-information in the header refers to bibliographical and non-bibliographical descriptions of the source document, as well as specifications of the encoding. The bibliographical section, or file description, of the header contains information on the author of the document, the title, as well as the different steps of the digital editing process (i.e. the transliteration, the XML conversion, as 
well as any revisions), together with the name of the person responsible for each process. The file description further details the extent of the document; this essentially corresponds to the notion of length, but various measurement can be used simultaneously here, such as the number of words in a document, the number of pages, as well as the number of sheets (i.e. a detail relevant to letters, in particular). Depending on the author, these measurements can stand in a different relation to each other - for example, someone with small handwriting will fill the same number of pages with a larger number of words than someone with a larger hand.

Also, within the file description, the so-called source or manuscript description can be found, which stores information such as where the physical manuscript is kept, a brief summary of the content of the document, as well as a physical description. The physical description identifies the document type (in our case either a diary entry or letter), as well as any noteworthy aspects of the appearance, for example, whether a seal is present, the handwriting is legible, or whether drawings are included.

Meanwhile, the non-bibliographical section, or profile description, makes it possible to store information on the date and place of creation of the document, provided they are available, and information on any 'participating' people - this includes the author, the recipient (for letters), as well as any people mentioned within the text. Since this section of the header can be added to incrementally, it later enables users to quickly filter documents according to participating people or places, which is also useful for literary scholars and (cultural) historians researching a particular person or group of people.

Finally, the encoding description documents the relationship between the electronic text and the source or sources from which it was derived. It may contain a simple paragraph detailing, for instance, whether text has been normalized and formatting has been preserved, as well as character declarations for nonstandard characters such as the long $\mathrm{s}<\lceil>$.

The facsimile section contains the manuscript source of each document in the form of links to digital images of the original manuscript. It is further possible to identify particular zones on each sheet of paper. This is useful when dealing with manuscripts where the writing is divided into distinct spaces; in the case of letters, for instance, part of one page is typically reserved for the address field and this sheet is later folded to form an envelope, hiding the letter writing on the remaining part of that page, as well as any additional sheets, on the inside (see Figure 2). 


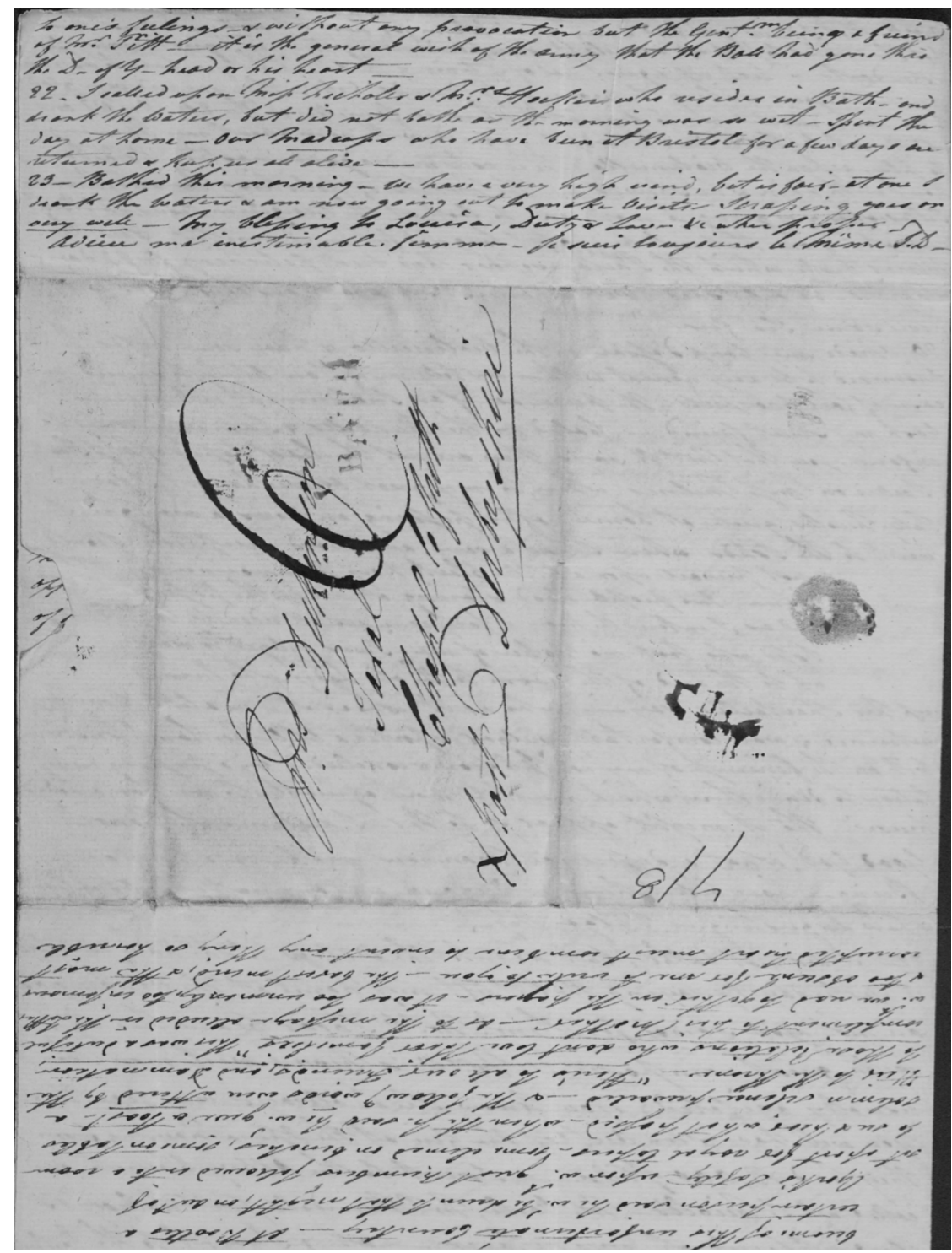

Figure 2: Illustration of text arrangement on a letter sheet used as an envelope; letter from John Dickenson (husband) to Lady Mary Hamilton, then Dickenson (21 June 1789; $H A M / 1 / 2 / 16)^{8}$ 
The main part of any file, however, is always the annotated text. To produce it, the initial transliteration must be carefully worked through again by an annotator familiar with the proposed scheme, replacing the pseudo-mark-up and further adding to it as they produce the XML-annotated version. For this step, a good $\mathrm{XML}$ editor is desirable, as it greatly reduces the risk of incomplete mark-up (for example incorrect or missing closing elements) that renders the entire XML document invalid, but that is difficult to find manually.

The possibilities for annotation provided by TEI and the customizations made to meet the needs of this project in particular, are vast. For brevity's sake, only a short overview of the structural and in-text elements available will be given here.

If necessary, a division between front matter and body of the text can be made. This is particularly relevant for letters, where the front matter consists of the cover, if it is preserved, on which the address is written, and seals and postmarks are put. Historically, this is a part that has often fallen victim to exclusion in printed editions, even though it can provide interesting socio-historical information, such as redirections of a letter. Figure 3 shows an example of a letter written by Lady Mary Hamilton's uncle Sir William Hamilton from Naples, which was first sent to her former address at Clarges Street, London, where she had lived with the two Miss Clarkes, and was then redirected to her new address in Taxal, Derbyshire, where she moved soon after her marriage with John Dickenson, which took place on 13 June 1785. Place of residence or visits and travels could be stored in a database to be connected to the texts for retrieval of background information that might be relevant to (cultural) historians.

The body of the text can contain several structural elements such as opening and closing formulas. These may be quite challenging to annotate, as such formal phrases often merge directly into the main text, and it is not always easy to define where an opening formula ends, and the letter text proper begins, as illustrated in Figure 4. Besides the textually obvious elements describing paragraphs and line breaks, there is also a more general element called 'span', which can associate any interpretive annotation with any span of text. 


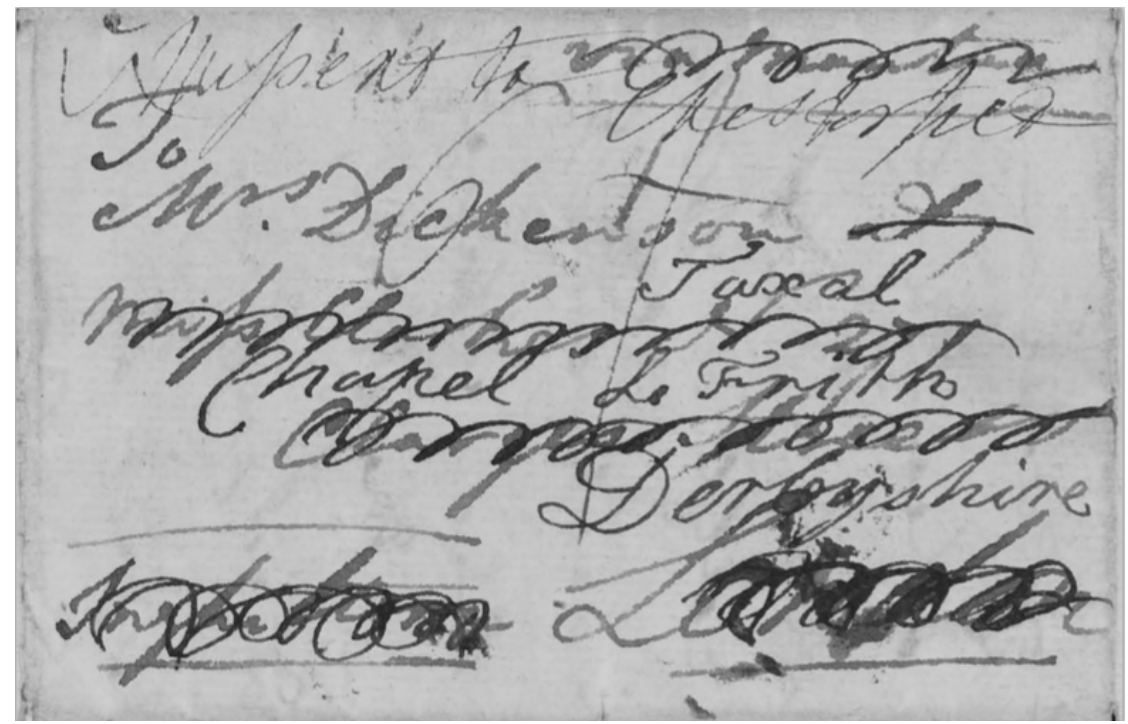

Figure 3: A redirected letter by Sir William Hamilton to Lady Mary Hamilton (2 August 1785; $H A M / 1 / 4 / 4 / 23)$

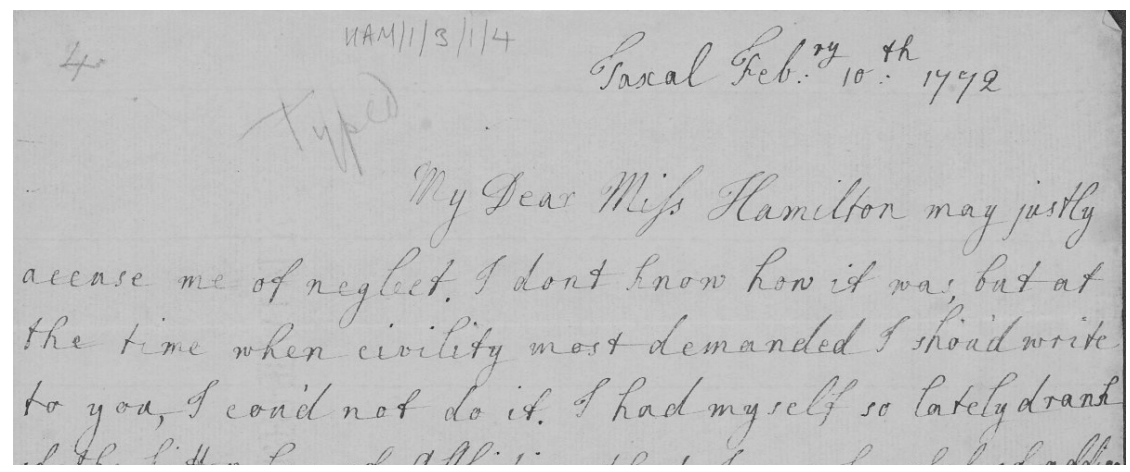

Figure 4: Letter from Sarah Dickenson (future mother-in-law) to Lady Mary Hamilton, 10 February 1772 (HAM/1/3/1/4)

The in-text annotation can be broadly divided into six categories: alternative encodings; additions, deletions, and modifications; hard to read, illegible, and 
damaged text; scriptural features; names and dates; and a few miscellaneous features.

The first three of these categories, in particular, make use of the non-linear nature of XML. 'Alternative encodings' refers to an element called 'choice', which groups alternatives with the original text, for example in abbreviations, non-standard spellings, and mistakes made by the original author. With this element, it is possible to record and make available both an abbreviation and its expansion, an original non-standard spelling and its normalization, a misspelling and its correction. This opens up the possibility to render the original version in the browsable transliteration or a concordance produced from a corpus search, while the normalization can still be accessed with a search function.

Additions, deletions, and modifications to the text by either the original author, or another person who later handled the manuscript, can also be specially marked. For instance, both the part of the text which has been crossed out, and the new text which replaced it, can be included without causing problems to a search engine or grammatical parser, which would not be able to handle alternative or duplicated passages.

There are elements applicable for use when portions of text are difficult or impossible to read, due to either the handwriting or damage to the original manuscript. Thus, when the transliterator is not sure, the uncertainty can be recorded instead of having to leave a gap in the digitized text. Furthermore, gaps due to torn, cut, or otherwise damaged text can also be clearly indicated. Occasionally, small amounts of text are missing, but can be inferred by the transliterator or, at a later stage, by the editor. In such cases, to ease both the reading flow, as well as the work of additional applications like taggers or parsers, the text can be supplied, and marked up as such.

Scriptural features refer to elements such as different ways of highlighting (for example bolding, italics, or underlining), superscript or subscript, but also significant spaces that were left empty in the original text. Such spaces can occur within a line, sometimes in order to indicate a change of subject, when the author was unwilling to begin a new paragraph (maybe to save space), or in between lines or paragraphs.

Proper names and dates also receive special mark-up. This feature can later be used to filter documents, for example according to people mentioned in the text. It also provides the possibility to note different aliases. In the Mary Hamilton Papers, for example, A Maria, Anna Maria, and Miss Clarke are all connected by the same identifier, and are thus linked to each other. ${ }^{9}$ 


\subsection{Online version}

Once the XML annotation has been completed, all information considered relevant gets stored and is reachable from one place. The next step consists in making this information accessible and properly readable. This is made possible by linking the XML-file to an XSLT ("eXtensible Stylesheet Language: Transformations') stylesheet, and opening it in a web browser.

The stylesheet is essentially a collection of rules for how to represent the information contained in the XML annotation. This includes commands as trivial as separately displaying each page of the diary entry or letter in question, instead of rendering it as one continuous text. Perhaps the simplest, and yet one of the most useful applications, is linking and displaying the photographic images of the manuscript, which allows for easy comparison of the transliteration to the original. More sophisticated applications involve the representation of the text. For example, a feature implemented in the stylesheet developed for the Mary Hamilton Papers serves to highlight particular features in the original text, some of which would typically have been normalized in a linear print edition. These features are marked in different colours to make them easily recognizable, and they include abbreviations, words with spellings that diverge from Present-day English conventions (e.g. because of capitalization or word divisions), and misspelled words. ${ }^{10}$ In addition, passages that were unclear to the transliterator, or supplied by the editor to fill gaps where the manuscript is partly damaged, are highlighted as well. Also marked up are proper names, and words or passages in a foreign language.

In order to further increase the benefit to the reader, mouse-over features have been implemented, so that when the cursor hovers over marked-up text, additional information is displayed, such as the expansion for abbreviations, the standard form for non-standard spellings, or the reasons for omitted or supplied text. The representational possibilities of stylesheets are considerable, and far from exhausted in the application to the Mary Hamilton Papers. ${ }^{11}$ Adapting the style sheet at a later stage will enable switching between different representations, such as an authentic and a normalized edition.

While the two previous sections presented the general aims and methodological approaches of the digitization project, the following offers a case study showing how the content of the Mary Hamilton Papers may be useful for studying linguistic variation and change in the late eighteenth and early nineteenth centuries. 


\section{Researching language change with the Mary Hamilton Papers: A case study}

The case study on Lady Mary Hamilton's language was prompted by a self-correction in her diary entry for 13 August 1784 (HAM/2/13), i.e. it grew out directly from the annotation process. However, the following discussion is not concerned with technical issues arising from the digitization process; instead the intention is to illustrate, on the basis of one specific example, how the materials which will be transliterated as part of the digitization project can be used to gain insights into an individual's language - by examining a particular linguistic feature in the socio-historical context of the time.

In her diary entry, Lady Mary Hamilton notes that she was visited by a Miss Murray and that "She pleased me very much by telling me I was a great favorite with of her fathers", Lord Stormont. Lady Mary Hamilton first writes "favorite with her fathers", but then crosses out the preposition with and replaces it with of (see Figure 5). Considering that the final line of the $r$ in fathers, unusually, extends beyond the $s$, it also appears as if she added this $s$ to father because she felt the genitive was required by the newly inserted preposition of. Since the colour of the ink and the width of the stroke are identical for both prepositions, Lady Mary Hamilton will most likely have made the corrections immediately after she finished writing this line or very soon after. Her diary entry for this day spreads across seven pages and includes a drawing of the hot air balloon she saw at the Lyceum. Towards the end of the entry, her writing grows less careful and neat, which speaks against her going back in order to make corrections on the first page, in neater handwriting, once she concluded the entry.



Figure 5: "favorite with of her fathers" (diary entry for 13 August 1784, HAM/2/13)

The case study explores why Lady Mary may have replaced with by of in the phrase favo $(u)$ rite + with/of + noun phrase (NP). In particular, it addresses the following issues:

(i) Does Lady Mary Hamilton's choice of preposition with favo(u)rite vary or change over time? 
(ii) Do eighteenth-century prescriptive works contain any examples, or even prescriptions, of this phrase?

(iii) Which preposition is generally used more frequently in this phrase at the time?

(iv) Could Lady Mary Hamilton's choice of preposition be influenced by her changing social networks? ${ }^{12}$

\subsection{Lady Mary Hamilton: A shift in prepositional usage}

Since only a small portion of the diary material has been transliterated so far, the 1925 biography by Anson and Anson was used as a supplementary source to find instances of the phrase favo(u)rite + with/of + NP in Lady Mary Hamilton's diaries. These additional instances were subsequently checked against the original manuscripts. Four further examples could be identified, and there does indeed appear to be a change in her prepositional usage over time. In her first diary from 1776, Lady Mary Hamilton uses the preposition with:

(1) Many persons remain here all Morning, till dinner time, playing at Farro and other games - Whist appears a favorite with foreigners as well as English (7 September 1776; HAM/2/1)

On the remaining occasions, however, Lady Mary Hamilton chooses of, and these examples (2-4) are all dated to 1784 , a period when she was living independently in London:

(2) Lady Catherine is a great favorite of mine (11 July 1784; HAM/2/11)

(3) I am quite proud of being a favorite of his (20 July 1784; HAM/2/12)

(4) I am so great a favorite of hers that... (9 August 1784; HAM/2/13)

Only four days after the last instance attested in the biography follows the instance of self-correction from with to of, discussed above and repeated in (5):

(5) She pleased me very much by telling me I was a great favorite of her fathers (13 August 1784; HAM/2/13)

In other words, it appears as if Lady Mary Hamilton consistently uses of in 1784, and with in her earlier entries (e.g. in 1776). This suggests that her choice of preposition underwent a change sometime in the intervening years. Although additional examples are needed to substantiate this observation, it offers an interesting working hypothesis for which support might be found by consulting 
the work of eighteenth-century prescriptivists and considering previous research on self-corrections (Section 4.2), as well as data on contemporary usage (Section 4.3) and from her social networks (Section 4.4).

\subsection{The normative tradition and self-corrections}

The eighteenth century saw a significant rise in publications prescribing the correct use of English grammar, and Johnson's Dictionary (1755) quickly became an authoritative work on the English lexicon. ${ }^{13}$ While the phrase favo $(u)$ rite + with/of + NP is not explicitly discussed in Johnson's Dictionary or treated in grammars like those by Lowth (1762), Priestley (1761, 1771) or Ash (1783), the correct use of prepositions was generally considered important. Lowth, for instance, comments on prepositions appropriate in particular phrasal verbs or after certain nouns (1762: 129-131); similar comments can be found in Priestley's grammar (1771: 155-163).

Moreover, letter writers often self-corrected their use of prepositions. In a letter from 1773, Joshua Reynolds makes a similar self-correction as Lady Mary Hamilton, also altering a preposition: after having written "the esteem and good will of all sorts of people" he proceeds to supplant of with from without changing any other words (Auer 2008: 218). Auer (2008) identifies further examples of preposition replacement in Late Modern English letters, for instance in "the meeting here [^'at' [[crossed]] out $\left.{ }^{\wedge}\right]$ on Monday next" in a letter addressed to Richard Orford (225) and in "I fear at this time of year \& at ${ }^{\wedge \text { in^ }}$ so bad a season" in a letter written by Lucy Whitaker (229). These brief examples illustrate the fact that writers at the time were aware of the importance of selecting the appropriate preposition for each context and were monitoring their own usage accordingly; the monitoring, in turn, becomes apparent through self-corrections in ego documents. ${ }^{14}$

Interestingly, Priestley (1771: 155-156) points out that native speakers generally do not have any problems with the correct use of prepositions, and that mistakes typically occur where one speaker follows another in misapplying a preposition. However, he also notes that in some cases two prepositions are used interchangeably (e.g. expert at/in), and that "custom has not decided in favour of either of them" (1771: 156). In the preface to the first edition of his grammar, Priestley writes about the importance of analogy in resolving such cases: "but since good authors have adopted different forms of speech, and in a case that admits of no standard but that of custom, one authority may be of as much weight as another; the analogy of language is the only thing to which we can have recourse, to adjust these differences" (1761: vi, original italics). 
In the context of the current case study, this raises the question of whether analogy may at some point in time have had an effect on which preposition eventually becomes the preferred option in favo(u)rite + with/of + NP; analogy with expressions such as in favour of or find favour with may have played a role in deciding for or against a particular preposition. ${ }^{15}$ However, while analogy is a possible factor influencing the overall development of the phrase, the next two sections will address the following points, focussing on the factors of frequency and social network:

(i) Are the two prepositions interchangeable in the eighteenth and nineteenth centuries, and does their frequency change over time?

(ii) Does Lady Mary Hamilton choose the preposition which is most frequent at the time? If not, which role does her social network play in her choice of preposition?

\subsection{Contemporary usage: Baseline data from CLMET3.0}

With 34 million words of published texts by male and female British authors, the Corpus of Late Modern English Texts (CLMET3.0) offers useful baseline data with which Lady Mary Hamilton's linguistic profile can be compared. The corpus is divided into three subperiods of roughly equal size: I (1710-1780), II (1780-1850) and III (1850-1920). The first subperiod coincides with the phase in which Lady Mary Hamilton chooses with as a collocate following favo(u)rite, and the second subperiod encompasses the diary entries in which she opts for $o f$. Figure 6 displays the normalized frequencies (per million words) of the prepositions with and of in favo(u)rite + with/of $+\mathrm{NP}$ in subperiods I and II. The changes which can be observed from the first to the second subperiod prove statistically significant in a log-likelihood test: the usage of with strongly increases after $1780(p<0.001)$, whereas of decreases in frequency $(p<0.0001) .{ }^{16}$ Lady Mary Hamilton's shift from with to of therefore moves contrary to the general developments observable in CLMET3.0. 


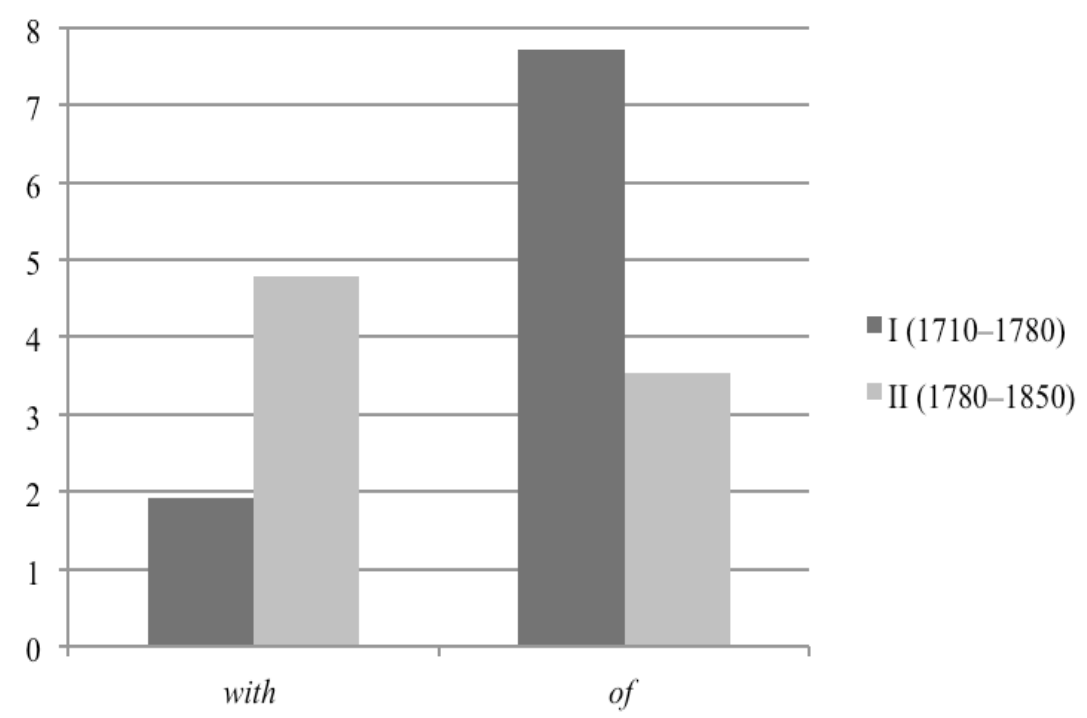

Figure 6: Attestations of favo(u)rite with vs. of in CLMET3.0 (per million words)

The data from CLMET3.0 also provide evidence for the fact that, in favo(u)rite + with/of + NP, the prepositions with and of could be used interchangeably at the time in most contexts, regardless of what type of noun phrase followed. Both prepositions are attested in cases where the head of the following noun phrase is a noun, as in (6-8):

(6) a favourite with her mother (Frances Burney, Cecilia, 1782; clmet3_0_2_96)

(7) a favourite of her father (Ann Radcliffe, The Mysteries of Udolpho, 1794; clmet3_0_2_115)

(8) a favourite of my mother's (Henry Fielding, The History of Tom Jones, a Foundling, 1749; clmet3_0_1_23)

Additionally, examples (7) and (8) show variable genitive marking after of. When the head of the noun phrase is a personal pronoun, both with (9) and of (10) are regularly attested in CLMET3.0: 
(9) M. Valancourt never was a favourite with me (Radcliffe, Udolpho, 1794; clmet3_0_2_115)

(10) he will be quite a favourite of mine (Horace Walpole, Letters, 173569; clmet3_0_1_44)

Examples (7) and (9) reveal that the same author might make use of both with and of in the same work, further highlighting the variable use of these prepositions at the time. There is only one context where of appears to have been the sole variant; whenever favo(u)rite is preceded by the definite article, as in example (11), of occurs in all instances in the corpus:

(11) the favourite of your father (Oliver Goldsmith, The Good Natur'd Man, 1768; clmet3_0_2_174)

If these cases are omitted from the calculations underlying Figure 5, the overall results still remain the same: with increases in usage after 1780, while of decreases (now at $p<0.01$ ). ${ }^{17}$

Incidentally, the entry for favourite/favorite in the Oxford English Dictionary $(O E D, 1989,2 \mathrm{nd}$ edn) corroborates the results of our corpus study, i.e. that the two prepositions were used interchangeably: "1.a. A person or thing regarded with peculiar favour, one preferred above others. Const. [construed with] of, with". ${ }^{18}$ The question to be answered, then, is why Lady Mary Hamilton's usage moved against the general development observable in a large corpus of Late Modern English writing. The following section examines whether her social networks may have had an influence on her changing prepositional usage.

\subsection{Lady Mary Hamilton's social networks}

When Lady Mary Hamilton leaves her home in 1777 to work at the royal court as third lady in waiting for the daughters of King George III and Queen Charlotte, she starts to form new social networks with other members of, as well as visitors to, the court. ${ }^{19}$ A network she would be associated with for the rest of her life is the Bluestocking circle, originally founded by Elizabeth Montagu, Elizabeth Vesey and Frances Boscawen, presumably in the mid-1750s. They frequently invited leading intellectuals of the time to their homes, and the Bluestocking circle also offered support for female education and women writers (Eger 2014). ${ }^{20}$ When exactly Lady Mary Hamilton made the acquaintance of Elizabeth Montagu and other members of the network is difficult to ascertain. The first note from Vesey to Hamilton contained in the Mary Hamilton Papers is dated 6 May $1780(\mathrm{HAM} / 1 / 6 / 2 / 1)$, and at this point they already appear well acquainted. This note pre-dates Hamilton's London diaries (1782-85), and there 
is no earlier evidence in Anson and Anson (1925) or in Elizabeth Montagu's correspondence as edited by Blunt (1923). By the time Lady Mary Hamilton leaves court in late 1782 and, early in 1783, together with the Clarkes sisters, moves into a house in Clarges Street, London, she is already a regular guest of the founding members of the Bluestockings, both at assemblies and more intimate occasions such as supper at the Veseys. ${ }^{21}$ Lady Mary Hamilton documents her encounters with them, and who else she met at such gatherings, in numerous diary entries - for instance in HAM/2/2, the diary she started upon leaving court employment.

Lady Mary Hamilton was well educated and enjoyed reading; the texts in CLMET3.0 consequently have the additional advantage of resembling the type of written language she may have been exposed to through books. Many members of the Bluestocking circle known to Lady Mary Hamilton are represented in CLMET3.0, which facilitates the comparison of their linguistic profiles with other authors of the time. The writers associated with the Bluestockings which are also represented in CLMET3.0 can be identified with the help of Eger (2014) and Sairio (2009a): these are James Boswell, Edmund Burke, David Garrick, Oliver Goldsmith, Elizabeth Griffith, Charlotte Lennox, Joshua Reynolds, Samuel Johnson and Horace Walpole (subperiod I), as well as Frances Burney (subperiod II). The following analysis of prepositional choice in favo(u)rite + with/of + NP by network members as opposed to other authors in CLMET3.0 concentrates on subperiod I, since the works of all network members except Frances Burney are included in this subperiod.

Figure 7 reveals how differently network members and other authors make use of the two prepositions: network members use of much more frequently than with, and significantly more so than other authors $(p<0.01) .{ }^{22}$ Much like Lady Mary Hamilton in her London diary, these network members almost exclusively employ of rather than with, which would increase in frequency after 1780. In switching from with to of, Lady Mary Hamilton therefore seems to adopt the preposition preferred by one of her new social networks she was part of when living at court and in Clarges Street. One member of her network employs favo(u)rite of especially frequently: 23 of 33 attestations occur in Horace Walpole's published Letters. Lady Mary Hamilton met him regularly, at their respective homes and at Bluestocking gatherings (Anson and Anson 1925: e.g. 142, 166-167, 288-289); furthermore, in her diary entry for 13 March 1783 (HAM/2/2), she notes that she read his Anecdotes of Painting in England. Therefore she was frequently exposed to his language, not only through conversation, but also through reading his publications, as well as his letters to her (Anson and Anson 1925: 321). Further research, also involving other linguistic 
variables, might reveal whether Walpole was a network contact who exerted a particularly strong linguistic influence on Lady Mary Hamilton (and possibly other Bluestockings), and to what extent she adopted usage patterns from other members of her social networks.

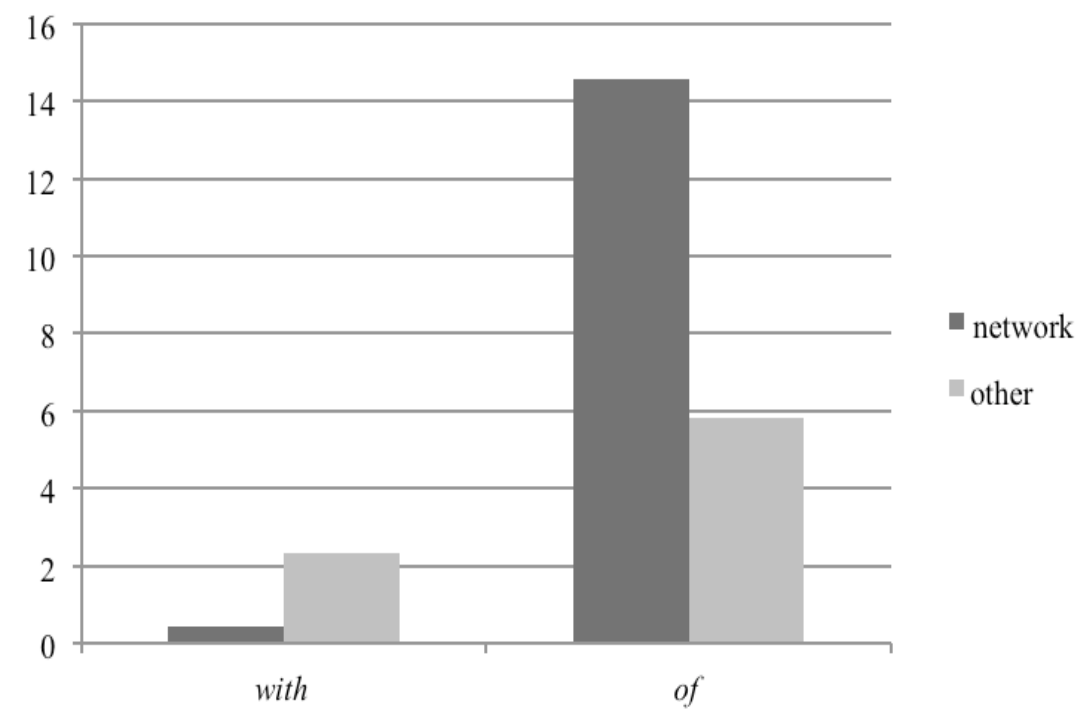

Figure 7: Attestations of favo(u)rite with vs. of in CLMET3.0 in works by members of Lady Mary Hamilton's social network and by other authors in subperiod I (per million words)

\subsection{Summary and outlook}

Evidence suggests that Lady Mary Hamilton's linguistic profile changed over time. Her changing use of prepositions in the phrase favo(u)rite + with/of $+N P$ is a case in point: in her first diary from 1776, before she moves to London, Lady Mary Hamilton chooses the preposition with, whereas during her London period (1784) she switches to of, thereby moving against general diachronic trends. However, by doing so she adapts linguistically to her new social network in London, the Bluestockings, whose members overwhelmingly prefer the preposition of.

Once more diaries and letters written by Lady Mary Hamilton have been transliterated, it will be possible to ascertain whether the observations made about her switch in prepositional usage - currently based on few examples and 
one instance of self-correction - are also supported by additional data. It would be interesting to supplement the findings from CLMET3.0 with data from corpora such as the Corpus of Early English Correspondence Extension (CEECE) to gain deeper insights into the language of eighteenth century letters and the writers' social networks. Finally, a significant corpus of Lady Mary Hamilton's writing will also allow the investigation of additional linguistic variables, providing a larger body of material with which to assess the role of social network influence on any variation and change observable in Lady Mary Hamilton's language.

\section{Conclusion}

The diaries and letters available in the Mary Hamilton Papers offer a wealth of material, which is of wider interdisciplinary interest. By providing detailed metadata, in-text annotation and links with images of the original manuscript pages, the digitization project aims at providing an online resource which can be used for linguistic, literary, cultural and historical research alike. Once the first stage of the project is complete - i.e. a sizeable corpus of diaries and letters are transliterated and digitized - further stages in the development of the project will include part-of-speech tagging and syntactic parsing in order to facilitate more complex linguistic research. Additional material from the collection can be added (and annotated) at a later stage, too, as part of a process of incremental corpus building.

Ongoing research (Gardner, in preparation) aims at compiling a linguistic biography of Lady Mary Hamilton, by (1) analysing Lady Mary Hamilton's linguistic profile diachronically over the course of the 21 years represented by the diaries, (2) investigating her changing social networks and their possible influence on her, and (3) positioning Lady Mary Hamilton's linguistic profile in the wider context of language change and variation in the eighteenth and nineteenth centuries. The case study in this paper illustrates that the Mary Hamilton Papers are indeed a powerful resource for an in-depth analysis of Lady Mary Hamilton's language and her social networks, as well as language change in general. That an investigation of a single author is a fruitful undertaking and yields novel insights is also exemplified e.g. by Tieken-Boon van Ostade (2014) and Sairio (in preparation), who focus on the language of the letters by Jane Austen and Elizabeth Montagu, respectively. The present digitization project and associated linguistic investigations will thus offer new perspectives and points of departure to the wider research community interested in history, culture, life and language in late eighteenth-century England. 


\section{Notes}

1. This collection was digitized by The National Archives (http://www.nationalarchives.gov.uk, accessed 5 October 2015).

2. Elspaß (2012) provides an overview of important existing corpora of ego documents.

3. The Mary Hamilton Papers are held at The University of Manchester, The John Rylands University Libary (reference number GB 133 HAM). Detailed catalogue information is available at http://archives.li.man.ac.uk/ ead/html/gb133ham-p1.shtml\#id4190467 (accessed 5 October 2015), and digitized images at http://luna.manchester.ac.uk/luna/servlet/Manchester 11 11 (accessed 5 October 2015). The project reported on in this article is related to - but not identical with - a similar initiative at Manchester University, but unlike the aim of the image-to-text project (http:// www.alc.manchester.ac.uk/linguistics-and-english-language/research/ projects/image-to-text/), the digitization project at Zurich aims at providing a searchable, fully annotated corpus of letters and diaries in the long term.

4. So far only one publication is based on the Mary Hamilton Papers: adopting a literary and cultural perspective, Crawley (2014) describes the content of this collection, the value of the material for future research and what it reveals about Lady Mary Hamilton's life and society in eighteenth-century England.

5. For an outline of Lady Mary Hamilton's life, see Baker (2004); a longer biography was compiled by her great-granddaughters (Anson and Anson 1925). Lady Emma Hamilton (1765-1815; née Amy Lyon), best known for being Lord Nelson's mistress, had married Lady Mary Hamilton's uncle Sir William in 1791 (Baker 2004; Pocock 2004).

6. This diary was originally written in shorthand and has been edited in book form, but the text is also available online in various formats, e.g. through Project Gutenberg (as plain text and HTML) or in an annotated version (http://www.pepysdiary.com/diary/; accessed 7 October 2015); the diary has recently even been popularized on twitter (https://twitter.com/samuelpepys; accessed 7 October 2015).

7. Information on how the online edition can be accessed, once published, will be supplied on our project website (http://www.es.uzh.ch/en/Subsites/ Projects/LadyHamilton.html).

8. The manuscript images are reproduced by courtesy of The John Rylands University Library, Manchester, under a Creative Commons licence (CCBY The University of Manchester). 
9. Lastly, there is also a small group of miscellaneous features, which is made up of elements for titles used in the text, quotations, and words or passages in a foreign language.

10. This is a very rare annotation, as the line between non-standard and 'wrong' spelling is very hard to define, and the present practice has been, if in doubt, to annotate in favour of the author.

11. One aspect that has not been exploited yet is the possibility of representing the original spatial arrangement of the text in relation to the page on the one hand, and other text on the other hand. So far, only fairly rough approximations of the text's placement on the page have been considered, for example if only the lower half of a particular page is written on. Although noted in the XML, we have not yet implemented the representation in the browsable version for text which is angled or cross-hatched relative to the rest.

12. Applying Milroy's (1987) social network theory, Bax (2000, 2005), Fitzmaurice (2004), Sairio (2008, 2009a) and Tieken-Boon van Ostade (2008) are studies that successfully traced linguistic variation and change in eighteenth-century individuals to network influence.

13. For an overview of prescriptivism in the eighteenth century see e.g. Beal (2004) and Finegan (1999). The influence of prescriptivism on letter writing, for instance, has been investigated by Auer (2008), Sairio (2008, 2009a) and Tieken-Boon van Ostade (2006, 2008), amongst others.

14. How valuable insights into a writer's language can be gained through the analysis of self-corrections has recently been shown by Tieken-Boon van Ostade (2014) on the basis of Jane Austen's correspondence. For a detailed categorization of different types of self-corrections pertaining to grammar, spelling, style and other factors see Fairman (2008).

15. Three chapters in Hundt et al. (2017) provide a detailed discussion of analogy and frequency as real psychological factors in language change (M. Hilpert, J. Bybee and C. Moder, H. De Smet and O. Fischer).

16. Statistical significance was calculated with log likelihood, using Paul Rayson's online log likelihood calculator (http://ucrel.lancs.ac.uk/llwizard.html, accessed 22 July 2015). There are no significant changes in usage between subperiods II and III, so of remains less common than with. The full set of frequencies is provided in Appendix I.

17. The adapted absolute frequencies for of are 49 (subperiod I), 28 (II) and 16 (III), normalized to 4.68 (I), 2.48 (II) and 1.27 (III).

18. Although only of is used in the four illustrative citations (dating from 1667, 1769,1838 and 1876) where favo(u)rite is followed by a preposition, this should not be taken as an indication that of is used more frequently than 
with. Firstly, the way citations were collected for the $O E D$ was not systematic and cannot be said to be representative of all periods and strata of society; secondly, data from CLMET3.0 revealed that in the investigated phrase with is more dominant than of from the late eighteenth century onwards and remains so until at least the early twentieth century.

19. All biographical information on Lady Mary Hamilton is derived from Baker (2004), Anson and Anson (1925) and her diaries.

20. The Bluestocking circle has been well studied from a linguistic perspective by Sairio (e.g. 2008, 2009a/b).

21. Incidentally, the Veseys also lived in Clarges Street (Eger 2014).

22. Fisher's Exact Test was used to determine statistical significance; Appendix II presents the detailed frequencies underlying Figure 6 . The overall results do not change if the phrase under investigation is introduced by the definite article, network members still use of noticeably more often than other authors (19 occurrences are recorded for each group, normalized to $8.39 \mathrm{vs.}$ 2.31 respectively).

\section{References}

Anson, Elizabeth and Florence Anson. 1925. Mary Hamilton, afterwards Mrs. John Dickenson, at court and at home: From letters and diaries, 1756 to 1816. London: John Murray.

Ash, John. 1783. Grammatical institutes: Or, an easy introduction to Dr. Lowth's English grammar. London: Printed for C. Dilly.

Auer, Anita. 2008. 'The letter that I wrote': Self-corrections in Late Modern English letters. In M. Dossena and I. Tieken-Boon van Ostade (eds.). Studies in Late Modern English correspondence: Methodology and data, 213-234. Bern: Peter Lang.

Baker, Anne Pimlott. 2004. Hamilton, Mary (1756-1816). Oxford dictionary of national biography. Oxford: Oxford University Press. http:// www.oxforddnb.com/view/article/48934 (accessed 24 July 2015).

Bax, Randy C. 2000. A network strength scale for the study of eighteenth-century English. European Journal of English Studies 4 (3): 277-289.

Bax, Randy C. 2005. Traces of Johnson in the language of Fanny Burney. International Journal of English Studies 5 (1): 159-181.

Beal, Joan C. 2004. English in modern times 1700-1945. London: Arnold. 
Blunt, Reginald (ed.). 1923. Mrs. Montagu 'Queen of the Blues': Her letters and friendships from 1762 to 1800. Vol. 2: 1777-1800. Boston: Houghton Mifflin.

Bradford, Richard (ed.). 2010. Life writing: Essays on autobiography, biography and literature. Basingstoke: Palgrave Macmillan.

CEEC $=$ Corpus of Early English Correspondence. 1998. Compiled by Terttu Nevalainen, Helena Raumolin-Brunberg, Jukka Keränen, Minna Nevala, Arja Nurmi and Minna Palander-Collin. Helsinki: University of Helsinki. http://www.helsinki.fi/varieng/CoRD/corpora/CEEC/index.html (accessed 23 July 2015).

CEECE = Corpus of Early English Correspondence Extension. 2000-. Compiled by Terttu Nevalainen et al. Helsinki: University of Helsinki. http:// www.helsinki.fi/varieng/CoRD/corpora/CEEC/ceece.html (accessed 23 July 2015).

CLMET3.0 = The Corpus of Late Modern English Texts, Version 3.0. 2011. Compiled by Hendrik De Smet, Hans-Jürgen Diller and Jukka Tyrkkö.

Crawley, Lisa. 2014. A life recovered: Mary Hamilton 1756-1816. Bulletin of the John Rylands Library 90 (2): 27-46.

$\mathrm{CSC}=$ The Corpus of Scottish Correspondence. 2007. Compiled by Anneli Meurman-Solin.

Eger, Elizabeth. 2014. Bluestocking circle [Bluestockings] (act. c.1755c.1795). Oxford dictionary of national biography. Oxford: Oxford University Press. http://www.oxforddnb.com/view/theme/63013 (accessed 24 July 2015).

Elspaß, Stefan. 2012. The use of private letters and diaries in sociolinguistic investigation. In J. M. Hernández and J. C. Conde-Silvestre (eds.). The handbook of historical sociolinguistics, 156-169. Oxford: Wiley-Blackwell.

Fairman, Tony. 2008. Strike-throughs: What textual alterations can tell us about writers and their scripts, 1795-1835. In M. Dossena and I. Tieken-Boon van Ostade (eds.). Studies in Late Modern English correspondence: Methodology and data, 193-212. Bern: Peter Lang.

Finegan, Edward. 1999. English grammar and usage. In S. Romaine (ed.). The Cambridge history of the English language. Volume IV: 1776-1997, 536588. Cambridge: Cambridge University Press. 
Fitzmaurice, Susan. 2004. The meanings and uses of the progressive construction in an early eighteenth-century English network. In A. Curzan and K. Emmons (eds.). Studies in the history of the English language II: Unfolding conversations, 131-174. Berlin: Mouton de Gruyter.

Gardner, Anne-Christine (in preparation). Language variation and change in late eighteenth-century England: A socio-historical investigation of Lady Mary Hamilton's diaries and letters [working title].

Honkapohja, Alpo (ed.). 2013. The Trinity Seven Planets. Scholarly Editing: The Annual of the Association for Documentary Editing 34. http:// www.scholarlyediting.org/2013/editions/sevenplanets.html (accessed 9 November 2014)

Hundt, Marianne, Sandra Mollin and Simone Pfenninger (eds.). 2017. The changing English language: Psycholinguistic perspectives. Cambridge: Cambridge University Press.

Johnson, Samuel. 1755. A dictionary of the English language. London: W. Strahan.

Kindlimann, Moira C. 2014. The digitization of eighteenth-century manuscript letters. Licentiate thesis, University of Zurich.

Lass, Roger. 2004. Ut custodiant litteras: Editions, corpora and witnesshood. In M. Dossena and R. Lass (eds.). Methods and data in English historical dialectology, 21-48. Bern: Peter Lang.

Loetz, Francisca. 2015. A new approach to the history of violence: 'Sexual assault' and 'sexual abuse' in Europe, 1500-1850. Leiden: Brill.

Lowth, Robert. 1762. A short introduction to English grammar. London: J. Hughs.

Marttila, Ville. 2014. Creating digital editions for corpus linguistics: The case of Potage Dyvers, a family of six Middle English recipe collections. Doctoral thesis, University of Helsinki. https://helda.helsinki.fi/handle/10138/ 135589.

Milroy, Leslie. 1987. Language and social networks. 2nd edn. Oxford: Blackwell.

OED = Oxford English dictionary online. 2010-. 3rd edn. http://www.oed.com (accessed 21 September 2015).

Pepys, Samuel. 1660. Diary of Samuel Pepys. Project Gutenberg. http:// www.gutenberg.org/ebooks/4125 (accessed 22 September 2015). 
Pocock, Tom. 2004. Hamilton, Emma, Lady Hamilton (bap. 1765, d. 1815). Oxford dictionary of national biography. Oxford: Oxford University Press. http://www.oxforddnb.com/view/article/12063 (accessed 21 September 2015).

Priestley, Joseph. 1761. The rudiments of English grammar; adapted to the use of schools: With observations on style. London: Printed for R. Griffith.

Priestley, Joseph. 1771. The rudiments of English grammar, adapted to the use of schools; With notes and observations, for the use of those who have made some proficiency in the language. London: Printed for J. and F. Rivington, T. Lowndes, S. Croweder, T. Becket and Co. and J. Johnson.

Sairio, Anni. 2008. Bluestocking letters and the influence of eighteenth-century grammars. In M. Dossena and I. Tieken-Boon van Ostade (eds.). Studies in Late Modern English correspondence: Methodology and data, 137-162. Bern: Peter Lang.

Sairio, Anni. 2009a. Language and letters of the Bluestocking Network: Sociolinguistic issues in eighteenth-century epistolary English. Helsinki: Société Néophilologique.

Sairio, Anni. 2009b. Methodological and practical aspects of historical network analysis. In A. Nurmi, M. Nevala and M. Palander-Collin (eds.). The language of daily life in England (1400-1800), 107-135. Amsterdam: Benjamins.

Sairio, Anni (in preparation). Bluestocking quills: The linguistic biography of Elizabeth Montagu, 1730s-1780s [working title].

Sutherland, Katherine (ed.). 2010. Jane Austen's fiction manuscripts: A digital edition. http://www.janeausten.ac.uk (accessed 22 September 2015).

TEI = Text Encoding Initiative. http://www.tei-c.org/index.xml (accessed 24 June 2014).

Tieken-Boon van Ostade, Ingrid. 2006. Eighteenth-century prescriptivism and the norm of correctness. In A. van Kemenade and B. Los (eds.). Blackwell handbook of the history of English, 539-557. Oxford: Blackwell.

Tieken-Boon van Ostade, Ingrid. 2008. Letters as a source for reconstructing social networks: The case of Robert Lowth. In M. Dossena and I. TiekenBoon van Ostade (eds.). Studies in Late Modern English correspondence: Methodology and data, 51-76. Bern: Peter Lang.

Tieken-Boon van Ostade, Ingrid. 2014. In search of Jane Austen: The language of the letters. New York: Oxford University Press. 
Ulbrich, Claudia, Kaspar von Greyerz and Lorenz Heiligensetzer (eds.). 2015. Mapping the 'I': Research on self-narratives in Germany and Switzerland. Leiden: Brill.

Van der Wal, Marijke J. and Gijsbert Rutten (eds.). 2013. Touching the past: Studies in the historical sociolinguistics of ego-documents. Amsterdam: Benjamins.

\section{Appendices}

\section{Appendix I}

Absolute and normalized frequencies (per million words) of with and of in favo(u)rite + preposition + noun phrase in CLMET3.0

\begin{tabular}{|c|c|c|c|c|c|}
\hline \multirow[b]{2}{*}{ Subperiod } & \multirow{2}{*}{ Words } & \multicolumn{2}{|l|}{ with } & \multicolumn{2}{|l|}{ of } \\
\hline & & abs. & norm. & abs. & norm. \\
\hline I (1710-1780) & $10,480,431$ & 20 & 1.91 & 81 & 7.73 \\
\hline II (1780-1850) & $11,285,587$ & 54 & 4.78 & 40 & 3.54 \\
\hline III (1850-1920) & $12,620,207$ & 50 & 3.96 & 28 & 2.22 \\
\hline
\end{tabular}

\section{Appendix II}

Absolute and normalized frequencies (per million words) of with and of in favo $(u)$ rite + preposition + noun phrase in CLMET3.0 in subperiod I: network members vs. other authors

\begin{tabular}{|c|c|c|c|c|c|}
\hline \multirow{2}{*}{ Group } & \multirow[b]{2}{*}{ Words } & \multicolumn{2}{|l|}{ with } & \multicolumn{2}{|l|}{$o f$} \\
\hline & & abs. & norm. & abs. & norm. \\
\hline Network members & $2,264,702$ & 1 & 0.44 & 33 & 14.57 \\
\hline Other authors & $8,215,729$ & 19 & 2.31 & 48 & 5.84 \\
\hline
\end{tabular}

